Please do not remove this page

RMIT

UNIVERSITY

\title{
Avionics sensor fusion for small size unmanned aircraft Sense-and-Avoid
}

Ramasamy, Subramanian; Sabatini, Roberto; Gardi, Alessandro

https://researchrepository.rmit.edu.au/esploro/outputs/9921861665401341/filesAndLinks?institution=61RMIT_INST\&index=null

Ramasamy, S., Sabatini, R., \& Gardi, A. (2014). Avionics sensor fusion for small size unmanned aircraft Sense-and-Avoid. Proceedings of 2014 IEEE International Workshop on Metrology for Aerospace, MetroAeroSpace 2014, 271-276. https://doi.org/10.1109/MetroAeroSpace.2014.6865933

Document Version: Accepted Manuscript

Published Version: https://doi.org/10.1109/MetroAeroSpace.2014.6865933

Repository homepage: https://researchrepository.rmit.edu.au (C) 2014 IEEE

Downloaded On 2023/04/26 09:37:57 +1000

Please do not remove this page 
Thank you for downloading this document from the RMIT Research Repository.

The RMIT Research Repository is an open access database showcasing the research outputs of RMIT University researchers.

RMIT Research Repository: http://researchbank.rmit.edu.au/

\section{Citation:}

Ramasamy, S, Sabatini, R and Gardi, A 2014, 'Avionics sensor fusion for small size unmanned aircraft Sense-and-Avoid', in Domenico Accardo (ed.) Proceedings of 2014 IEEE International Workshop on Metrology for Aerospace, MetroAeroSpace 2014, United States, 29 -30 May 2014, pp. 271-276.

See this record in the RMIT Research Repository at:

https://researchbank.rmit.edu.au/view/rmit:28752

Version: Accepted Manuscript

Copyright Statement: (C) 2014 IEEE

Link to Published Version:

http://dx.doi.org/10.1109/MetroAeroSpace.2014.6865933 


\title{
Avionics Sensor Fusion for Small Size Unmanned Aircraft Sense-and-Avoid
}

\author{
Subramanian Ramasamy, Roberto Sabatini, Alessandro Gardi \\ RMIT University - SAMME, Melbourne, Australia \\ roberto.sabatini@rmit.edu.au
}

\begin{abstract}
Cooperative and non-cooperative Sense-and-Avoid (SAA) systems are key enablers for Unmanned Aircraft (UA) to routinely access non-segregated airspace. In this paper the stateof-the-art cooperative and non-cooperative SAA technologies for small size $U A$ are presented and the associated multisensor data fusion techniques are discussed. The non-cooperative sensors including both passive and active Forward Looking Sensors (FLS) and the cooperative systems including Traffic Collision Avoidance System (TCAS), Automatic Dependent Surveillance Broadcast (ADS-B) system and/or Mode $C$ transponders form part of the SAA holistic architecture. After introducing the SAA system processes, the key mathematical models are presented. The Interacting Multiple Model (IMM) algorithm is used to estimate the state vector of the intruders and this is propagated to predict the future trajectories using a probabilistic model. Adopting these mathematical models, conflict detection and resolution strategies for both cooperative and un-cooperative intruders are identified. Additionally, a detailed error analysis is performed to determine the overall uncertainty volume in the airspace surrounding the intruder tracks. This is accomplished by considering both the navigation and the tracking errors affecting the measurements and translating them to unified range and bearing uncertainty descriptors, which apply both to cooperative and non-cooperative scenarios. Detailed simulation case studies are carried out to evaluate the performance of the proposed SAA approach on a representative host platform (AEROSONDE UA) and various intruder platforms, including large transport aircraft and other UA. Results show that the required safe separation distance is always maintained when the SAA process is performed from ranges in excess of 500 metres.
\end{abstract}

Keywords-sense-and-avoid; non-coopertive sensors; cooperative systems; sensor fusion; collision avoidance; conflict detection and resolution

\section{INTRODUCTION}

Unmanned Aircraft (UA) are increasingly used for a number of civil and military applications. In particular, small size UA are employed for their ability of performing tasks with higher manoeuvrability, longer endurance and pose less risk to human lives. To carry out a variety of tasks, it necessitates the UA's safe integration into the non-segregated airspace [1]. Both cooperative and non-cooperative Sense-and-Avoid (SAA) systems are being developed to address these integration aspects [2]. The SAA capability is defined as the automatic detection of possible conflicts by the UA platform under consideration and performing avoidance manoeuvre tasks to prevent the identified collisions. An analysis of the available SAA candidate technologies and the associated sensors for both cooperative and non-cooperative SAA systems are presented in [3]. Non-cooperative Collision Detection and Resolution (CD\&R) for UA is considered as one of the major challenges that needs to be addressed [4]. As a result, a number of non-cooperative sensors for the SAA system have been adopted. Light Detection and Ranging (LIDAR) is used for detecting, warning and avoiding obstacles for low-level flying [5]. Multi-Sensor data fusion becomes an integral element when considering a variety of sensor candidates. Multi-sensor platform for obstacle detection by using Millimetre Wave (MMW) radar, Forward Looking Infra-Red (FLIR), LIDAR and an Electronic Surveillance Module (ESM) is adopted in [6]. A non-cooperative collision avoidance system for UA by utilising pulsed Ka-band radar and optical sensors is proposed in [7]. An approach to the definition of encounter models and their applications on the SAA strategies is presented in [8] considering both cooperative and non-cooperative scenarios. Ground-Based SAA (GBSAA) systems using electronic sensors are also currently being developed. These ground based systems provide information for manoeuvre decisions for terminal-area operations [1]. To obtain the states of the tracked obstacles, Extended Kalman Filter (EKF) is used in order to predict the trajectory in a given time horizon [9]. On-board trajectory re-planning with dynamically updated constraints based on the intruder and the host dynamics is at present used to generate obstacle avoidance trajectories [10]. A coarseresolution radar based SAA solution is developed for small size UA [11] and its information is fused with data from Automatic Dependent Surveillance - Broadcast (ADS-B) system [12]. As part of this research, the possible synergies attainable with the adoption of different detection, tracking and trajectory generation algorithms are studied and as a fundamental objective, the errors propagation from different sources and the impacts of host and intruders dynamics on the ultimate SAA solution are also addressed.

\section{REQUIREMENTS AND SAA CANDIDATE TECHNOLOGIES}

In an operational perspective, guidelines and regulations are required to support the SAA system requirements development [13]. The requirements for designing and developing an effective SAA system are derived from the current regulations applicable for the see-and-avoid capability of manned aircraft. Table 1 summarises the proposed range and Field of Regard (FOR) requirements for the SAA system [2, 14, 15]. The proposed detection range and FOR have to be adequate to ensure separation from the intruder to prevent a probable near mid-air collision. This criterion is also naturally applicable in 
This is the author pre-publication version. This paper does not include the changes arising from the revision, formatting and publishing process. The final paper that should be used for referencing (available from: http://ieeexplore.ieee.org/xpl/articleDetails.jsp?arnumber=6865933) is:

S. Ramasamy, R. Sabatini and A. Gardi, “Avionics Sensor Fusion for Small Size Unmanned Aircraft Sense-and-Avoid”, in proceedings of IEEE Metrology for Aerospace (MetroAeroSpace) 2014, pp. 271-276, Benevento, Italy, 2014. DOI: 10.1109/MetroAeroSpace.2014.6865933

the case of small UA since the vast majority of mid-air collision events occur below $3000 \mathrm{ft}$ [14].

TABLE I. RANGE AND FOR REQUIREMENTS FOR SAA SYSTEM

\begin{tabular}{|c|c|c|c|c|}
\hline \multirow{2}{*}{ Altitude } & Manned & \multicolumn{3}{|c|}{ UAS } \\
\cline { 2 - 5 } & $\begin{array}{c}\text { Nominal } \\
\text { pilot }\end{array}$ & $\begin{array}{c}\text { Autono- } \\
\text { mous }\end{array}$ & Line-of-sight & $\begin{array}{c}\text { Beyond } \\
\text { line-of- } \\
\text { sight }\end{array}$ \\
\hline Low & 2.6 & 1.1 & 1.8 & 1.9 \\
\hline Medium & 4.2 & 1.8 & 2.9 & 3.1 \\
\hline High & 5.7 & 2.8 & 4.1 & 4.3 \\
\hline \multicolumn{5}{|c|}{ FOR requirements $\left(^{\circ}\right)$} \\
\hline Azimuth & \multicolumn{5}{|c|}{ \pm 110} \\
\hline Elevation & \multicolumn{5}{|c|}{} \\
\hline
\end{tabular}

The essential criteria for designing an effective SAA system are:

- The Field of View (FOV) has to be equivalent or superior to that of a pilot in the cockpit and it corresponds to primary FOV $-60^{\circ}$ in vertical and $70^{\circ}$ in horizontal and secondary FOV $-100^{\circ}$ in vertical and $120^{\circ}$ in horizontal [16].

- $\quad$ Common FOV/FOR for visual and thermal cameras.

- Accurate and precise intruder detection (static and dynamic), recognition and trajectory prediction (dynamic).

- Prior obstacle detection for allowing time for executing the trajectory avoidance manoeuvres.

- Effective fusion schemes for Multi-Sensor data augmentation, especially by tight coupling [12].

- Identification of the primary means of cooperative and non-cooperative SAA system for integrity requirements.

Developing and evaluating sensors and the associated data fusion algorithms will be a key constituent of the SAA system design [17]. A number of cooperative systems and noncooperative sensors can be employed for obtaining a holistic SAA system solution. The cooperative systems used are TCAS (Traffic Collision Avoidance System) / ACAS (Airborne Collision Avoidance System), ADS-B system and/or Mode C transponders. The inclusion of ADS-B redefines the paradigm of Communication, Navigation and Surveillance (CNS) in Air Traffic Management (ATM) today by providing trajectory information. The non-cooperative SAA sensors are employed to detect intruders or other obstacles in the UA FOR when cooperative systems are unavailable in the intruders [4]. Optical, thermal, LIDAR, MMW Radar and acoustic sensors are used as part of non-cooperative SAA system. The SAA technologies are listed in Table II representing $\mathrm{C}$ for cooperative and $\mathrm{NC}$ for non-cooperative (both active and passive) sensors [18]. Based on the identified technologies, Boolean logics based decision tree architecture for SAA system (consisting of a number of AND gates) is illustrated in Fig. 1.
TABLE II. SAA CANDIDATE TECHNOLOGIES

\begin{tabular}{|c|c|c|c|c|}
\hline Sensor/System & Type & Range & Bearing & Trajectory \\
\hline Visual camera & NC, Passive & - & Accurate & Extracted \\
\hline Thermal camera & NC, Passive & - & Accurate & Extracted \\
\hline LIDAR & NC, Active & Accurate & Narrow & Extracted \\
\hline MMW Radar & NC, Active & Accurate & Narrow & Extracted \\
\hline Acoustic & NC, Active & Accurate & $360^{\circ}$ & Extracted \\
\hline $\begin{array}{c}\text { Transponder } \\
\text { (Mode C) }\end{array}$ & $\mathrm{C}$ & Accurate & Calculated & Extracted \\
\hline ADS-B & $\mathrm{C}$ & Accurate & Calculated & Provided \\
\hline TCAS/ACAS & $\mathrm{C}$ & Accurate & Accurate & Extracted \\
\hline
\end{tabular}

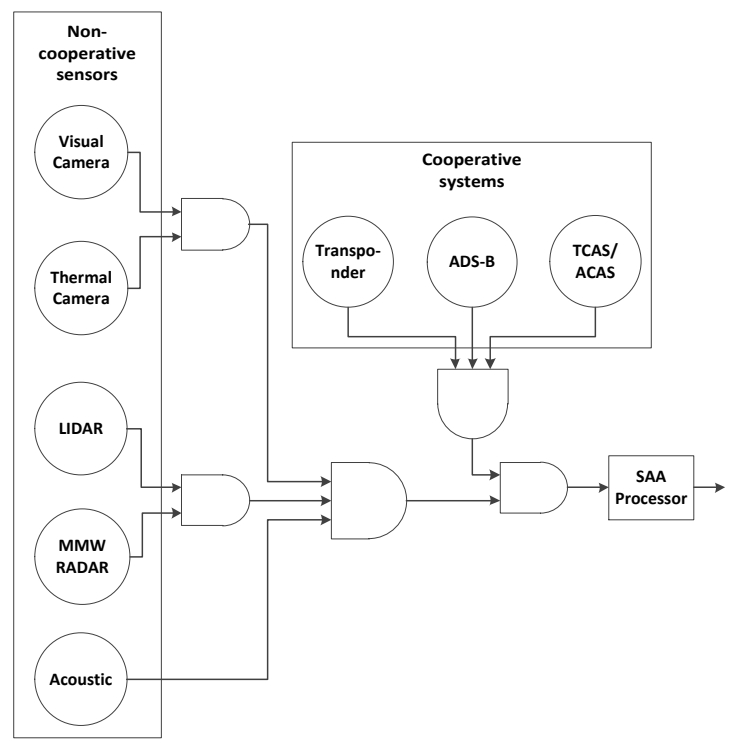

Fig. 1. Avionics sensors and systems decision tree architecture

\section{SAA SYSTEM}

The sequential steps involved in the SAA process for executing an efficient Tracking, Deciding and Avoiding (TDA) loop are illustrated in Fig. 2.

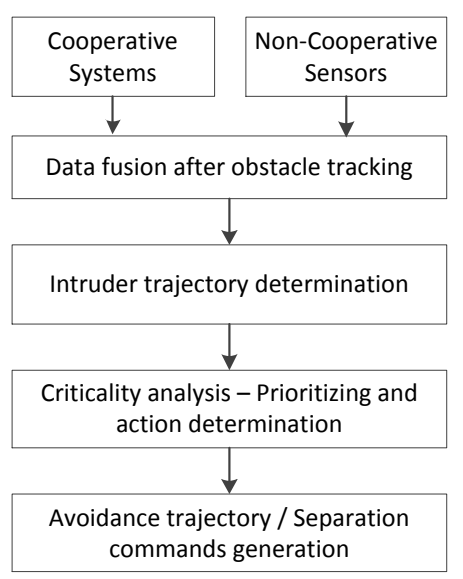

Fig. 2. SAA system process.

After performing multisensor data fusion, the trajectory of the intruders is determined. Criticality analysis is carried out 
This is the author pre-publication version. This paper does not include the changes arising from the revision, formatting and publishing process. The final paper that should be used for referencing (available from: http://ieeexplore.ieee.org/xpl/articleDetails.jsp?arnumber=6865933) is:

S. Ramasamy, R. Sabatini and A. Gardi, “Avionics Sensor Fusion for Small Size Unmanned Aircraft Sense-and-Avoid”, in proceedings of IEEE Metrology for Aerospace (MetroAeroSpace) 2014, pp. 271-276, Benevento, Italy, 2014. DOI: 10.1109/MetroAeroSpace.2014.6865933

to prioritize (i.e. to determine if a collision risk threshold is exceeded for all the tracked intruders) and to determine the action commands. If an avoidance action is required, the SAA system generates and optimises an avoidance trajectory according to a cost function defined by \{minimum distance, fuel, time and closure rate with the aid of differential geometry algorithms $[14]$ to generate a smooth trajectory.

\section{A. Non-Cooperative sensors}

Gimballed visual and thermal cameras are used for determining position and velocity estimates of the intruders. To obtain all-weather operation, thermal imaging is used in conjunction with the visual one. The proposed hardware for the camera provides an approximate FOV of $70^{\circ}$ with a resolution of 2.0 MP. The fusion of optical sensors with other noncooperatives sensors increases the angular accuracy. LIDAR sensor, scaled from [6], is proposed for extracting range measurements and provides a FOV of $40^{\circ}$ in azimuth and $15^{\circ}$ in elevation. It allows the operator to select the azimuth orientation of the FOV among three possible directions: aligned with the platform heading (normal flight envelope) or $20^{\circ} \mathrm{left} / \mathrm{right}$ with respect the platform heading. This option provides an optimized coverage for turning manoeuvres at high angular speed. For stabilised obstacle detection, after image acquisition, the noise caused by the platform motion is removed [14]. Bottom-hat morphology is performed to detect negative contrast features that correspond to the threats. Lowlevel tracking is achieved by utilising Ad-hoc Viterbi filtering method by employing a bank of filters. Let $\alpha_{n}^{b}(i, j)$ be the filter output at time step, $n$ of pixel $(i, j)$ for the filter bank branch $b$, and $I_{n}(i, j)$ be the greyscale level of pixel $(i, j)$, the Ad-hoc Viterbi filter steps, for $1 \leq i \leq H, 1 \leq j \leq W$ and all $n$, are carried out. The statistical test criterion for evaluation to determine the actual presence of a collision threat is given by:

$$
\gamma_{n}=\max _{1 \leq i \leq H, 1 \leq j \leq W}\left[\alpha_{n}(i, j)\right]
$$

where $\gamma_{n}$ is the comparison parameter and is equivalent to 0.75 [14]. An illustration of the acquired, stabilised and tracked visual image is shown in Fig. 3 and 4.

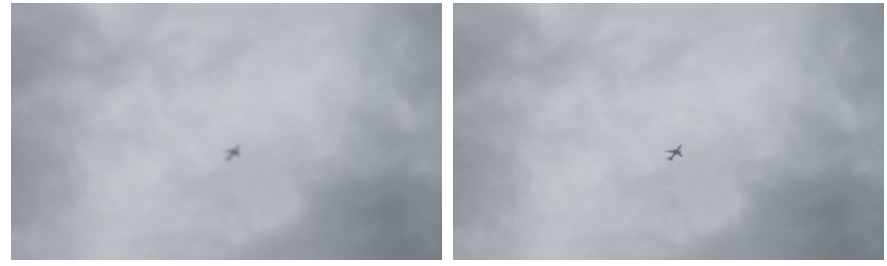

Fig. 3. Acquired and stabilised visual image.

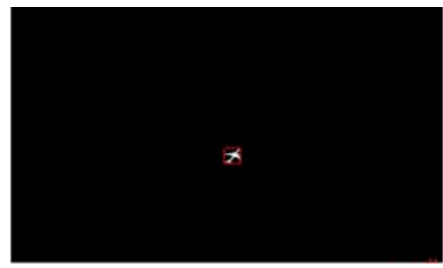

Fig. 4. Tracked target.

An example of an acquired thermal image [19], which is subjected to segmentation and tracking is illustrated in Fig. 5.
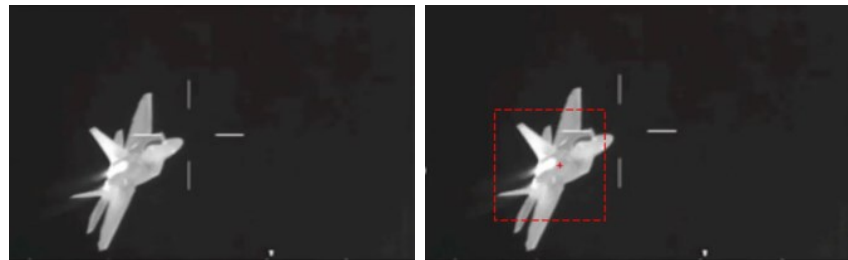

Fig. 5. Acquired thermal image and tracked target.

A low-cost navigation and guidance system is adopted for position estimates, which includes Global Navigation Satellite System (GNSS), Micro-Electromechanical System (MEMS) Inertial Measurement Unit (IMU) and Vision Based Navigation (VBN) sensors [20, 21]. When the set threshold is exceeded and the detection is continuous, high level tracking detection is performed by using a Kalman Filter. The predicted state, $\widehat{x}(t)$ at time $t$ is given by:

$$
\begin{aligned}
\widehat{x}(t)=\left[\begin{array}{l}
P_{x}(t) \\
P_{y}(t) \\
V_{x}(t) \\
V_{y}(t)
\end{array}\right] & =\left[\begin{array}{llll}
1 & 0 & 1 & 0 \\
0 & 1 & 0 & 1 \\
0 & 0 & 1 & 0 \\
0 & 0 & 0 & 1
\end{array}\right]\left[\begin{array}{l}
P_{x}(t-1) \\
P_{y}(t-1) \\
V_{x}(t-1) \\
V_{y}(t-1)
\end{array}\right] \\
& +\left[\begin{array}{cc}
\frac{t^{2}}{2} & 0 \\
0 & \frac{t^{2}}{2} \\
t & 0 \\
0 & t
\end{array}\right]\left[\begin{array}{l}
a_{x} \\
a_{y}
\end{array}\right]+\varepsilon(t)
\end{aligned}
$$

where $P_{x, y}(t)$ is the position in the $x$ and $y$ directions respectively as a function of time, $t . V_{x, y}(t)$ is the velocity in the $x$ and $y$ direction respectively, $a_{x, y}(t)$ is the acceleration and $\varepsilon(t)$ is the prediction Gaussian noise. The Kalman Filter equations are:

$$
\begin{gathered}
\hat{x}_{i}(k \mid k)=\hat{x}_{i}(k \mid k-1)+W_{i}(k)\left[z_{i}(k)-H_{i}(k) x_{i}(k \mid k-1)\right] \\
P_{i}(k \mid k)=P_{i}(k \mid k-1)-W_{i}(k) S_{i}(k) W_{i}^{T}(k)
\end{gathered}
$$

where:

$$
\begin{gathered}
W_{i}(k)=P_{i}(k \mid k-1) H_{i}^{T}(k) S_{i}^{-1}(k) \\
S_{i}(k)=\left[H_{i}(k) P_{i}(k \mid k-1) H_{i}^{T}(k)+R_{i}(k)\right]
\end{gathered}
$$

where $H_{i}(k)$ represents the design matrix and $R_{i}(k)$ is the measurement noise covariance matrix and $k$ is the sample time. The Track-To-Track $\left(\mathrm{T}^{3}\right)$ algorithm is employed for sensor fusion. The primary advantage of adopting this method is to combine the estimates instead of combining the observations from different sensors. The track fusion algorithm is defined as the weighted average variance of all the tracks and is given by:

$$
\begin{gathered}
\hat{x}_{F}(k \mid k)=P_{F}(k \mid k) \times \sum_{i=1}^{n} P_{i}^{-1}(k \mid k) \hat{x}_{i}(k \mid k) \\
P_{F}(k \mid k)=\left[\sum_{i=1}^{n} P_{i}^{-1}(k \mid k)\right]^{-1}
\end{gathered}
$$

Once the tracks are fused and the states are estimated, the imminent trajectory is predicted. The errors in predicted trajectory can be derived from the quality of the measurements, reflected in the prediction error, which are expressed as:

$$
\sigma^{2}(k+\tau \mid k)=\operatorname{var}\left[n(k+\tau)-\hat{n}^{l}(k+\tau \mid k)\right]
$$


This is the author pre-publication version. This paper does not include the changes arising from the revision, formatting and publishing process. The final paper that should be used for referencing (available from: http://ieeexplore.ieee.org/xpl/articleDetails.jsp?arnumber=6865933) is:

S. Ramasamy, R. Sabatini and A. Gardi, “Avionics Sensor Fusion for Small Size Unmanned Aircraft Sense-and-Avoid”, in proceedings of IEEE Metrology for Aerospace (MetroAeroSpace) 2014, pp. 271-276, Benevento, Italy, 2014. DOI: 10.1109/MetroAeroSpace.2014.6865933

where $n(k+\tau)$ is the exhibited (modelled) trajectory and $\hat{n}^{l}(k+\tau \mid k)$ is the predicted optimal trajectory at sample time $k+\tau$. For trajectory prediction, the obstacle centre of mass, the target orientation and the geometric shape of the uncertainty volume are determined. Once the trajectory is predicted, the Risk of Collision (ROC) is determined by calculating the probability of a near mid-air event for the predicted trajectory over the time horizon by employing Monte Carlo approximations.

\section{B. Cooperative systems}

ADS-B system is used to obtain the state of the intruders. The future position of the intruders is projected based on the estimate of the current state vector and the flight profile. The ADS-B measurement model adopted for intruder position and velocity estimates in $x$ and $y$ cardinal directions is given as:

$$
Z(k)=\left[\begin{array}{cccccc}
1 & 0 & 0 & 0 & 0 & 0 \\
0 & 1 & 0 & 0 & 0 & 0 \\
0 & 0 & 0 & 1 & 0 & 0 \\
0 & 0 & 0 & 0 & 1 & 0
\end{array}\right]\left[\begin{array}{c}
x \\
\dot{x} \\
\ddot{x} \\
y \\
\dot{y} \\
\ddot{y}
\end{array}\right]+\left[\begin{array}{c}
V_{x}(k) \\
V_{\dot{x}}(k) \\
V_{y}(k) \\
V_{\dot{y}}(k)
\end{array}\right]
$$

Assuming the velocity components, $V_{x}(k), V_{\dot{x}}(k), V_{y}(k)$ and $V_{\dot{y}}(k)$ as being affected only by Gaussian noise with zero mean, the standard deviation is defined by the covariance matrix given by:

$$
R=\left[\begin{array}{cccc}
E\left[V_{x}^{2}\right] & 0 & 0 & 0 \\
0 & E\left[V_{\dot{x}}^{2}\right] & 0 & 0 \\
0 & 0 & E\left[V_{y}^{2}\right] & 0 \\
0 & 0 & 0 & E\left[V_{\dot{y}}{ }^{2}\right]
\end{array}\right]
$$

where $E[]$ represents the mean. An Interacting Multiple Model (IMM) algorithm is adopted for data fusion. The IMM model is a state-of-the-art tracking algorithm when multiple kinematics behaviour are to be considered [12]. Using this model, the state vector of the intruders is determined and this is propagated to predict the future trajectories using a probabilistic model. After computing the mixing probability, the combination of the state estimate is given by:

$$
\hat{x}_{F}(k \mid k)=\sum_{i=j}^{r} \hat{x}^{j}(k \mid k) \mu_{j}(k)
$$

where $\mu_{j}(k)$ is the mode probability update. For conflict detection, the resultant covariance matrix, $Q$ after transformation is defined as:

$$
Q=R * S * R^{T}
$$

where $\mathrm{S}$ is the diagonal covariance matrix and $\mathrm{R}$ represents the transformation matrix between the heading aligned frame to that of the UA host platform frame. The probability of conflict is defined as the volume below the surface of the probability density function, $p(x, y)$ representing the conflict zone. The conflict probability, $P_{c}$ is expressed as:

$$
P_{c}=\int_{-\Delta y-\Delta y c}^{-\Delta y+\Delta y c} \int_{-\infty}^{+\infty} p(x, y) d x d y
$$

where $\Delta y+\Delta y c$ represents the conflict separation distance and $\Delta x c, \Delta y c$ correspond to the rows of the conflict boundary matrix. The conflict probability is simplified as:

$$
P_{c}=P(-\Delta y+\Delta y c)-P(-\Delta y+\Delta y c)
$$

\section{ERROR MODELLING}

Error analysis is performed to determine the overall uncertainty volume in the airspace surrounding the intruder tracks. This is accomplished by considering both the navigation and the tracking errors affecting the measurements and translating them to unified range and bearing uncertainty descriptors. In order to quantify the errors, let $\sigma_{E x}, \sigma_{E y}$ and $\sigma_{E z}$ represent the standard deviation of the navigation error $\left(\sigma_{n x}\right.$, $\left.\sigma_{n y}, \sigma_{n z}\right)$ or the tracking error $\left(\sigma_{t x}, \sigma_{t y}, \sigma_{t z}\right)$ in the $x, y$ and $z$ cardinal directions respectively. Using a spherical coordinates frame with origin at the host UA centre of mass, the range and bearing errors associated with the intruder tracking process is transformed into a local Cartesian coordinate frame (either host or intruder body frame). The error ellipsoid is defined as [22]:

$$
\frac{x^{2}}{\sigma_{E x^{2}}}+\frac{y^{2}}{\sigma_{E y^{2}}}+\frac{z^{2}}{\sigma_{E z}^{2}}=1
$$

With respect to the obtained navigation and tracking error ellipsoids, spherical hormonics coefficients are determined. Let $r(\theta, \psi)$ represent the smooth function defined on the ellipsoid and the parameterisation is given by:

$$
r(\theta, \psi)=\sum_{l=0}^{\infty} \sum_{m=-l}^{l} X_{l m} Y_{l m}(\theta, \psi)
$$

The function $r(\theta, \psi)$ is limited to a number of $\mathrm{N}$ finite coefficients. $X_{l m}$ is a factor and the function $Y_{l m}(\theta, \psi)$ is the spherical hormonic function and is given by:

$$
Y_{l m}(\theta, \psi)=\sqrt{\frac{(2 l+1)(l-m) !}{4 \pi(l+m) !}} P_{l m} \cos (\theta) e^{i m \psi}
$$

where $P_{l m}$ represents the Legendre functions. Expanding $e^{i m \psi}$ as $C_{l m} \cos (m \psi)+i S_{l m} \cos (m \psi)$, we have $C_{l m}$ and $S_{l m}$ defined as the spherical hormonic coefficients. The spherical hormonic coefficients are obtained as [23]:

$$
\begin{gathered}
S_{l m}=0 ; l, m \varepsilon N \\
C_{l m}=0 ; l, m \varepsilon 2 N+1
\end{gathered}
$$

and for all other $1, \mathrm{~m}$ :

$$
\begin{gathered}
C_{l m}=\frac{3}{a^{l}} \frac{\left(\frac{l}{2}\right) !\left(\frac{l}{m}\right) !\left(2-\delta_{o m}\right)}{2^{m}(l+3)(l+1) !} \times \\
\sum_{i=0}^{(l-m) / 4} \frac{\left(a^{2}-b^{2}\right)^{(m+4 i) / 2}\left[c^{2}-\left(\frac{1}{2}\right)\left(a^{2}-b^{2}\right)\right]^{(l-m-4 i) / 2}}{16^{i}\left(\frac{l-m-4 i}{2}\right) !\left(m+\frac{2 i}{2}\right) ! i !}
\end{gathered}
$$

where $\delta_{o m}$ is the Kronecker symbol and $(a, b, c)$ represents the semi-major radius of the navigation or tracking error ellipsoid. Therefore, both navigation and tracking error ellipsoids are generated as illustrated in Fig. 6. Finally, the overall uncertainty volume is obtained by combining the two error 
This is the author pre-publication version. This paper does not include the changes arising from the revision, formatting and publishing process. The final paper that should be used for referencing (available from: http://ieeexplore.ieee.org/xpl/articleDetails.jsp?arnumber=6865933) is:

S. Ramasamy, R. Sabatini and A. Gardi, “Avionics Sensor Fusion for Small Size Unmanned Aircraft Sense-and-Avoid”, in proceedings of IEEE Metrology for Aerospace (MetroAeroSpace) 2014, pp. 271-276, Benevento, Italy, 2014. DOI: 10.1109/MetroAeroSpace.2014.6865933

ellipsoids, which must be avoided by the host UA. The uncertainty volume is determined for the two cases of correlated and uncorrelated errors. A notional example of the two combined navigation and tracking error ellipsoids and the resulting uncertainty volume for uncorrelated measurements (obtained by inflating the navigation ellipsoid with the tracking error components) is illustrated in Fig. 7.

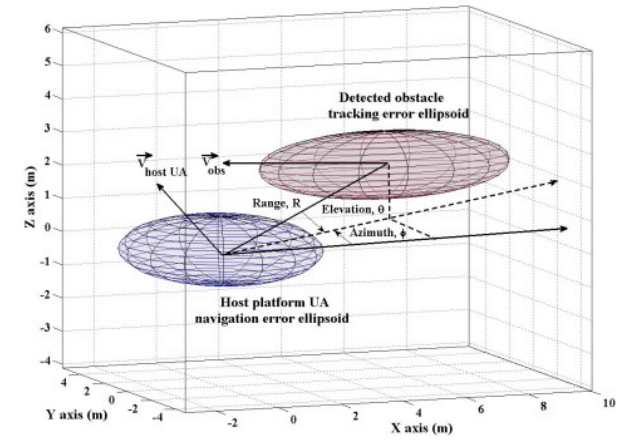

Fig. 6. Navigation and tracking error ellipsoids.

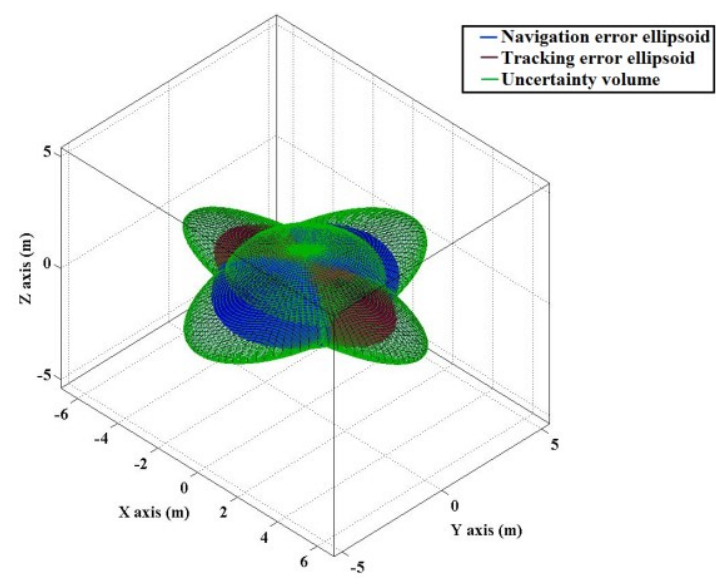

Fig. 7. Uncertainty volume for uncorrelated errors.

\section{Simulation Case Study}

Simulations were performed utilising an AEROSONDE UA six degrees of freedom (6-DoF) model as the host platform. The simulation considers a complex scenario where the host UA is equipped with cooperative and non-cooperative SAA system capable of achieving collision avoidance and conflict resolution. Three intruders are considered as part of the simulation assuming intruder 1 without any cooperative SAA system (AEROSONDE UA), intruder 2 equipped with ADS-B system (large commercial aircraft) and intruder 3 is equipped with cooperative SAA system capable of achieving collision avoidance and conflict resolution (AEROSONDE UA). The scenario is illustrated in Fig. 8. The intruder 1 states are derived using non-cooperative FLS of the host UA. The other two intruders are tracked with the aid of ADS-B messages. Required separation distance is achieved with respect to all the intruders after resolution is performed (both horizontal and vertical). As an illustration, the horizontal separation achieved with respect to the first intruder is shown in Fig. 9.

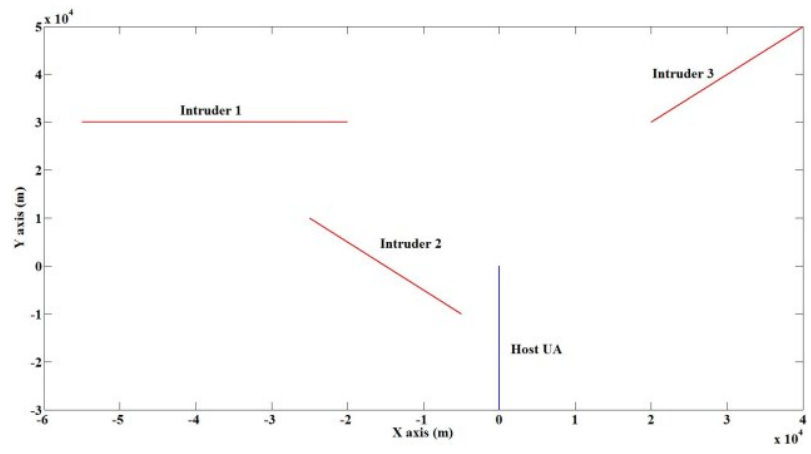

Fig. 8. Simulation scenario

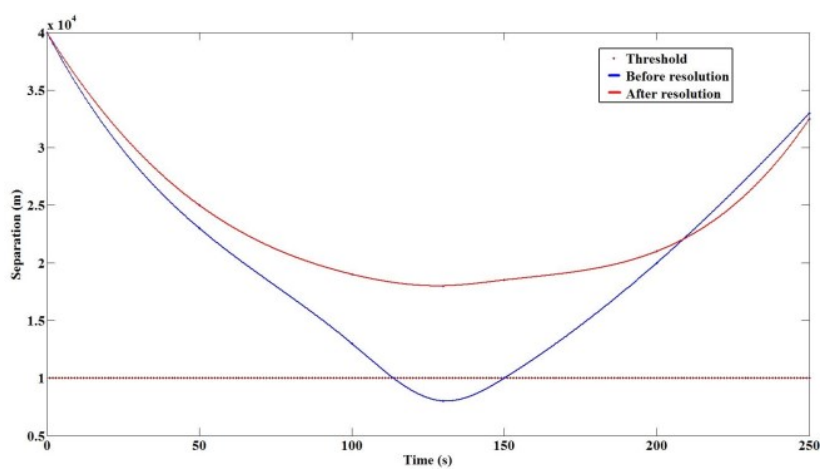

Fig. 9. Achieved horizontal separation of intruder 1.

After the obstacles are detected and tracked, an avoidance trajectory is generated and the corresponding action commands are executed. As a result, the intruder is evaded and the trajectory of the host UA is restored to its original intended path after performing step climb and level off phases as illustrated in Fig. 10. Results show that the required safe separation distance is always maintained when the SAA process is performed from ranges in excess of 500 metres.

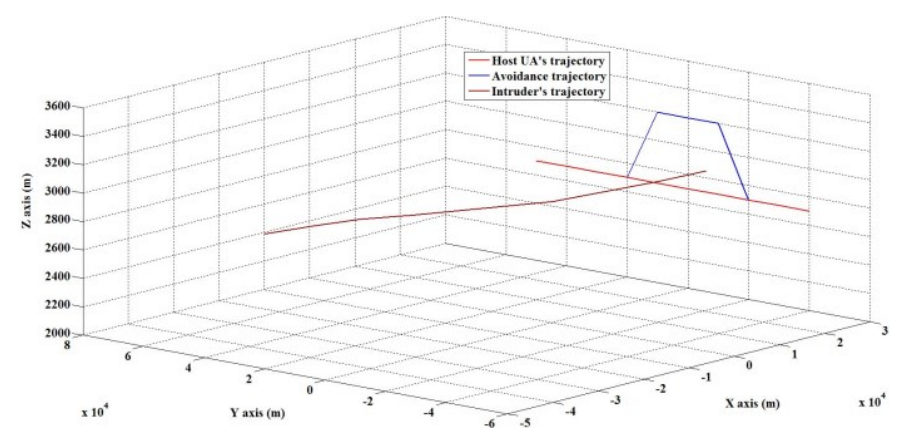

Fig. 10. Achieved vertical resolution.

\section{CONCLUSIONS}

The proposed SAA system for small UA is in accordance with the established requirements in order to avoid the detected obstacles. The available state-of-the-art SAA technologies were identified and a holistic architecture was proposed. The 
This is the author pre-publication version. This paper does not include the changes arising from the revision, formatting and publishing process. The final paper that should be used for referencing (available from: http://ieeexplore.ieee.org/xpl/articleDetails.jsp?arnumber=6865933) is:

S. Ramasamy, R. Sabatini and A. Gardi, "Avionics Sensor Fusion for Small Size Unmanned Aircraft Sense-and-Avoid", in proceedings of IEEE Metrology for Aerospace (MetroAeroSpace) 2014, pp. 271-276, Benevento, Italy, 2014. DOI: 10.1109/MetroAeroSpace.2014.6865933

sequential process required to design an effective SAA system was presented. The analytical models for both non-cooperative sensors and cooperative sensors were discussed. Error modelling was performed to obtain an overall uncertainty volume associated with the intruder track. The results pertaining to image processing algorithms adopted for noncooperative SAA system design were presented. A detailed simulation case study was presented and it is inferred that the SAA process is performed from ranges in excess of 500 metres demonstrating the effectiveness of the proposed SAA system. In future research, integration of the SAA system with other avionic and ground-based systems for Intent Based Operations $[24,25]$ will be performed. In particular, in order to meet the Communication, Navigation and Surveillance (CNS) integrity requirements, Avionics-Based Integrity Augmentation (ABIA) system will be adopted [26, 27]. Additionally, analytical models developed for laser obstacle warning and avoidance system will be incorporated [28]. Current research activities are focusing on adopting the proposed SAA system for other UA platforms such as the JAVELIN UA [29].

\section{REFERENCES}

[1] T.P. Spriesterbach, K.A. Bruns, L.I. Baron, and J.E. Sohlke, "Unmanned Aircraft System Airspace Integration in the National Airspace Using a Ground-Based Sense and Avoid System,” Johns Hopkins APL Technical Digest, vol. 32, no. 3, 2013.

[2] S.B. Hottman, K.R. Hansen, and M. Berry, "Literature review on detect, sense, and avoid technology for unmanned aircraft systems", Tech. Report DOT/FAA/AR-08/41, US Deptartment of Transport, USA, 2009.

[3] A. Muraru, "A Critical Analysis of Sense and Avoid Technologies for Modern UAVs", Advances in Mechanical Engineering, ISSN: 21600619, vol 2, no.1, March 2012. DOI:10.5729/ame.vol2.issue1.23

[4] J. Lai, J.J Ford, L. Mejias, P. O'Shea, and R. Walker, "See and Avoid Using Onboard Computer Vision," Sense and Avoid in UAS Research and Applications, Plamen Angelov (ed.), John Wiley and Sons, West Sussex, UK, 2012

[5] R. Sabatini, A. Gardi, and M.A. Richardson, "LIDAR Obstacle Warning and Avoidance System for Unmanned Aircraft," International Journal of Mechanical, Industrial Science and Engineering, vol. 8, no. 4, WASET International Science Index, pp. 62-73, April 2014

[6] R. Sabatini, "Airborne Laser Systems Performance Prediction, Safety Analysis, Fligth Testing and Operational Training," PhD Thesis, Schoo of Engineering, Cranfield Univeristy, UK, 2003.

[7] G. Fasano, D. Accardo, A. Moccia, C. Carbone, U. Ciniglio, F. Corraro, and S. Luongo, "Multi-Sensor-Based Fully Autonomous NonCooperative Collision Avoidance System for Unmanned Air Vehicles," Journal of Aerospace Computing, Information, and Communication, vol. 5, no. 10 , pp. 338-360, 2008. DOI: $10.2514 / 1.35145$

[8] M.J. Kochenderfer, L.P Espindle, J.D. Griffith, and J.K Kuchar, "Encounter Modeling for Sense and Avoid Development," in Proceedings of Integrated Communications, Navigation and Surveillance Conference (ICNS), pp. 1-10, 2008. DOI: 10.1109/ICNSURV.2008.4559177

[9] C.G. Prévost, A. Desbiens, E. Ganon, and D. Hodouin, "UAV Optimal Obstacle Avoidance while Respecting Target Arrival Specifications," in Preprints of the $18^{\text {th }}$ IFAC World Congress, Milano, Italy, pp. 11815$11820,2008$.

[10] C.K. Lai, M. Lone, P. Thomas, J. Whidborne, and A. Cooke, "On-Board Trajectory Generation for Collision Avoidance in Unmanned Aerial Vehicles," in Proceedings of the IEEE Aerospace Conference, pp. 1-14, 2011. DOI: 10.1109/AERO.2011.5747526

[11] R.A. Klaus and T.W. McLain, "A Radar-Based, Tree-Branching Sense and Avoid System for Small Unmanned Aircraft," AIAA Guidance, Navigation, and Control Conference, August 2013. DOI $10.2514 / 6.2013-4789$
[12] P. Cornic, P. Garrec, S. Kemkemian, L. Ratton, "Sense and Avoid Radar using Data Fusion with Other Sensors," in Proceedings of the IEEE Aerospace Conference, Big Sky, USA, March 2010. DOI: 10.1109/AERO.2011.5747514

[13] T. Anderson, K. Hoffler, and H. Verstynen, "UAS Sense and Avoid Requirements Assessment," 50 $0^{\text {th }}$ AIAA Aerospace Sciences Meeting including the New Horizons Forum and Aerospace Exposition, Nashville, Tennessee, USA, January 2012. DOI: 10.2514/6.2012-961

[14] L.R. Salazar, R. Sabatini, S. Ramasamy, and A. Gardi, "A Novel System for Non-Cooperative UAV Sense-And-Avoid," Paper presented at the European Navigation Conference 2013, Vienna, Austria, April 2013.

[15] Federal Aviation Administration, "Pilot's Role in Collision Avoidance," AC90-48C, Washington DC, USA, 1983.

[16] DOT/FAA/CT-96-1, "Human Factors Design Guide for Acquisition of Commercial-Offthe-Shelf subsystems," Non-Developmental Items, and Developmental Systems-Final Report and Guide, January 1996.

[17] Next Generation Air Transportation System, "NextGen UAS Research, Development and Demonstartion Roadmap," Joint Planning and Devlopment Office, 2012

[18] A. Larcher, D. Maroney, and A. Zeitlin, "Unmanned Aircraft Collision Avoidance - Technology Assessment and Evaluation Methods," FAA EUROCONTROL ATM R\&D Symposium, Barcelona, Spain, 2007.

[19] Flightglobal and FLIR Systems, "Farnborough Day 1 Flying Display in Infrared," 2012

[20] R. Sabatini, S. Ramasamy, A. Gardi, and L.R. Salazar, "Low-cost Sensors Data Fusion for Small Size Unmanned Aerial Vehicles Navigation and Guidance," International Journal of Unmanned Systems Engineering, vol. 1, no. 3, pp. 16-47, August 2013

[21] R. Sabatini, C. Bartel, A. Kaharkar, T. Shaid, and S. Ramasamy, "Navigation and Guidance System Architectures for Small Unmanned Aircraft Applications," International Journal of Mechanical, Industrial Science and Engineering, vol. 8, no. 4, pp. 733-752, International Science Index, April 2014

[22] E.J. Garboczi, "Three-dimensional mathematical analysis of particle shape using X-ray tomography and spherical harmonics: Application to aggregates used in concrete," Cement Concrete Research, vol. 32, no. 10, 1621-1638, 2002.

[23] Z. Zhenjiang, Y. Meng, C. Hutao, and C. Pingyuan, "The Method to Determine Spherical Harmonic Model of Asteroid based on Polyhedron," in Proceedings of the $3^{\text {rd }}$ International Conference on Computer and Electrical Engineering, International Proceedings of Computer Science and Information Technology, vol. 53, 2012.

[24] A. Gardi, R. Sabatini, S. Ramasamy, and K. de Ridder, "4-Dimensional Trajectory Negotiation and Validation System for the Next Generation Air Traffic Management," in Proceedings of the AIAA Guidance, Navigation \& Control Conference, Boston, Massachusetts USA, August 2013. DOI: $10.2514 / 6.2013-4893$

[25] S. Ramasamy, R. Sabatini, A. Gardi, and Y. Liu, "Novel Flight Management System for Real-Time 4-Dimensional Trajectory Based Operations," in Proceedings of the AIAA Guidance, Navigation \& Control Conference, Boston, Massachusetts, USA, August 2013. DOI: $10.2514 / 6.2013-4763$

[26] R. Sabatini, T. Moore, and C. Hill, "A Novel GNSS Integrity Augmentation System for Civil and Military Aircraft," International Journal of Mechanical, Industrial Science and Engineering, vol. 7, no. 12, International Science Index 84, pp. 1433-1449, December 2013.

[27] R. Sabatini, T. Moore, and C. Hill, "A New Avionics-Based GNSS Integrity Augmentation System: Part 1 - Fundamentals," The Journal of Navigation, vol. 66, no. 3, pp. 363-384, 2013. DOI: $10.1017 /$ S0373463313000027

[28] R. Sabatini, A. Gardi, and S. Ramasamy, "A Laser Obstacle Warning and Avoidance System for Manned and Unmanned Aircraft," in Proceedings of the IEEE Metrology for Aerospace Conference, Benevento, Italy, May 2014

[29] M. Burston, R. Sabatini, A. Gardi, and R. Clothier, "Reverse Engineering of a Fixed Wing Unmanned Aircraft 6-DoF Model on Laser Scanner Measurements," in Proceedings of the IEEE Metrology for Aerospace Conference, Benevento, Italy, May 2014. 